\title{
Description of a seven-year prospective study of human papillomavirus infection and cervical neoplasia among 10000 women in Guanacaste, Costa Rica
}

\author{
M. Concepción Bratti, ${ }^{1}$ Ana C. Rodríguez, ${ }^{1}$ Mark Schiffman, ${ }^{2}$ \\ Allan Hildesheim, ${ }^{2}$ Jorge Morales, ${ }^{1}$ Mario Alfaro, ${ }^{1}$ Diego Guillén, ${ }^{1}$ \\ Martha Hutchinson, ${ }^{3}$ Mark E. Sherman, ${ }^{2}$ Claire Eklund, ${ }^{3}$ \\ John Schussler, ${ }^{4}$ Julie Buckland, ${ }^{4}$ Lidia A. Morera, ${ }^{1}$ \\ Fernando Cárdenas, ${ }^{1}$ Manuel Barrantes, ${ }^{1}$ Elmer Pérez, ${ }^{1}$ \\ Thomas J. Cox, ${ }^{5}$ Robert D. Burk, ${ }^{6}$ and Rolando Herrero ${ }^{1}$
}

Suggested citation $\quad \begin{aligned} & \text { Bratti MC, Rodríguez AC, Schiffman M, Hildesheim A, Morales J, Alfaro M, et al. Description of a } \\ & \text { seven-year prospective study of human papillomavirus infection and cervical neoplasia among } 10000\end{aligned}$ seven-year prospective study of human papillomavirus infection and cervical neo
women in Guanacaste, Costa Rica. Rev Panam Salud Publica. 2004;15(2):75-89.

ABSTRACT Objective. The Guanacaste study ("Guanacaste Project," or GP), was designed to investigate the role of human papillomavirus (HPV) infection and its cofactors in the development of cervical neoplasia and to evaluate new cervical cancer screening technologies. The follow-up phase of the GP was designed to study why a small proportion of women infected with HPV develop cervical intraepithelial neoplasia grade 2 (CIN 2), CIN 3, or cancer (these three together are globally referred to as $\geq C I N 2$, that is, CIN 2 or worse). The purpose of this article is to describe this prospective study in detail and to present the preliminary findings regarding the incidence of cervical neoplasia.

Methods. A cohort of 10049 randomly selected women from 18 to 97 years old from Guanacaste, a province in northwestern Costa Rica, was intensively screened in 1993-1994 and then followed up for seven years after being enrolled. A questionnaire for demographic and risk factors was administered, and a pelvic examination was performed on sexually active women at each follow-up visit in order to obtain samples for screening tests and for research purposes. The final diagnosis given at the end of the enrollment phase categorized women into several groups according to the perceived risk of their developing either high-grade precursors of cancer or cancer. These groups were followed up at different intervals according to the risk of developing $\geq$ CIN 2. The most active follow-up (every 6-12 months) was concentrated on the women most likely to develop $\geq$ CIN 2, based on cytology $(\mathrm{n}=492)$. The remainder of the cohort was followed either annually $(\mathrm{n}=2574)$ or after five to seven years of passive follow-up

\footnotetext{
FUCODOCSA (Costa Rican Foundation for Training in Health Sciences), Proyecto Epidemiológico Guanacaste, San José, Costa Rica. Send correspondence to: M. Concepción Bratti, Proyecto Epidemiológico Guanacaste, P.O. Box 1253-1007, San José, Costa Rica; telephone: (506) 296 1036/296 1467; fax: (506) 296 1465; e-mail: mcbratti@amnet.co.cr
}

2 National Cancer Institute, Division of Cancer Epidemiology and Genetics, Bethesda, Maryland United States of America.

3 Women and Infants' Hospital, Providence, Rhode Island, United States.
4 Information Management Services Inc., Silver Spring, Maryland, United States.

University of California at Santa Barbara, Santa Barbara, California, United States.

6 Albert Einstein College of Medicine, Bronx, New York, United States. 
( $\mathrm{n}=3$ 926). All women with possibly severe lesions detected by any technique were referred to colposcopy for further evaluation and treatment, and they were also censored from the study. Lesions $\geq$ CIN 2 served as both the censoring outcome and our surrogate for cancer risk. Results. Participation during follow-up was high (near 90\%). Suspected $\geq$ CIN 2 by any screening technique censored $4.6 \%$ of women. Most of the women censored because of suspected $\geq$ CIN 2 came from the large group perceived at entry as being at low risk of developing $\geq$ CIN 2, but the greatest rates of progression to $\geq C I N 2$ were observed among women perceived at entry to be at highest risk of $\geq C I N 2$, based on their cytology, virology, or sexual behavior.

Conclusions. The GP is the largest population-based longitudinal cohort for the study of $H P V$ and cervical neoplasia in the world, and its results will hopefully let us soon plan future worldwide prevention strategies. Research projects such as this one require the long-term commitment of a large multidisciplinary team and ample financial resources. The intensive effort and expertise applied in all aspects of this study were key factors in its success as a model of cooperative, interdisciplinary cancer research in Latin America. Quality control played an important role at all times during the study and made it possible to adapt new diagnostic and screening technology to Guanacaste. The systematic follow-up of a population-based group of close to 10000 women in Guanacaste should permit careful, time-dependent evaluation of factors postulated to be linked to the development of cervical cancer as well as the evaluation of clinical markers of disease progression. The study results that have already been published have validated sensitive screening techniques and have also promoted the use of more affordable screening techniques in resource-poor, developing countries. The GP has also contributed to building knowledge for the search for vaccines against HPV as part of the effort to develop an effective tool to reduce the incidence and mortality of cervical cancer worldwide.

Key words Carcinoma; papillomavirus, human; precancerous conditions; risk factors; epidemiologic methods; Costa Rica.

The Guanacaste cohort study ("Guanacaste Project," or GP) was designed to investigate the role of human papillomavirus (HPV) infection and its cofactors in the development of cervical neoplasia and to evaluate new cervical cancer screening technologies in a true population sample of high-risk women in Guanacaste, which is a primarily rural province in the northwest of Costa Rica. The design and methods of the enrollment phase of this population-based natural history study have been described in detail (1). There have been a number of articles published on the intensive cross-sectional analysis of the enrollment data (2-28). We believe that the study has succeeded as a model of cooperative, interdisciplinary cancer research in Latin America. The most important work lies ahead and will come from analyses of the prospective follow-up. These results will increase the knowledge about cervical HPV infection and especially about progression to cancer precursors in a small proportion of infected women. The GP is the largest population-based longitudinal cohort for the study of HPV and cervical neoplasia in the world, and its results will hopefully let us soon plan future worldwide prevention strategies. The National Cancer Institute (NCI) of the United States of America has developed new techniques to produce viruslike particles that are being used to manufacture vaccines against HPV $(29,30)$. In the next phase of this GP collaboration, we plan to start a trial of a vaccine against HPV types 16 and 18 in Guanacaste. Here, we describe the prospective study in detail and present the preliminary findings regarding the occurrence of cervical neoplasia in this true population sample.

\section{MATERIALS AND METHODS}

\section{Overview of enrollment phase and major study components}

The critical features of cohort enrollment were: (1) a complete censal sampling to identify the population, (2) intensive screening by multiple state-of-the-art techniques, (3) referral to colposcopy of those women with any apparent abnormality, and (4) rigorous quality assurance of every study procedure.

The GP enrolled a population-based cohort, starting with complete ascertainment of 11742 women living in a random sample of census segments in Guanacaste (1). After exclusions and refusals, we intensively screened a cohort of 10049 women, who were from 18 to 97 years of age. Informed consent was obtained at the first visit. Women were asked to carefully read information about the study while waiting at a study clinic, and the full consent form was read to them by the interviewer, who answered their questions and addressed their concerns. During enrollment several clinics from different health institutions were available throughout Guanacaste to perform study procedures. The informed consent form mentioned the possibility of follow-up as part of the study. Participation was entirely voluntary, and women were reimbursed for their travel costs to and from the clinic if necessary. Most of the clinics were lo- 
cated close to the women's residences, but sometimes the women had to travel a long distance, especially for colposcopy visits, because both colposcopy clinics were located at the two regional hospitals, in the towns of Liberia and Nicoya. After obtaining informed consent, a standardized questionnaire for demographic and cervical cancer risk factors was administered. The interviewer-administered questionnaire at the screening examination addressed known cervical cancer risk factors, including sexual behavior, smoking, parity, and oral contraceptive use. After completing the questionnaire, sexually active women underwent a pelvic examination. That examination included a vaginal $\mathrm{pH}$ assessment and collection of exfoliated cervical cells with a Cervex brush (Rovers Medical Devices B.V., Oss, the Netherlands) for cytologic diagnosis with three different techniques: conventional, semiautomated PapNet (Neuromedical Systems, Suffern, New York, United States), and ThinPrep (Cytyc Corporation, Boxborough, Massachusetts, United States) thin-layer cytology done with residual cellular material on the Cervex brush. Additional cervical cells were collected with a Dacron swab to determine the presence of HPV DNA by different techniques, including the Hybrid Capture (HC) Tube test and HC 2 (Digene, Gaithersburg, Maryland, United States), as well as polymerase chain reaction (PCR) assays. Also during this examination, two Cervigrams (National Testing Laboratories, High Ridge, Missouri, United States) were taken after application of $5 \%$ acetic acid to the cervix. Finally, a blood sample was collected to perform immunologic, genetic, and other assays.

All women with possibly severe lesions detected visually during the pelvic examination were urgently referred to colposcopy for further evaluation. Women with any abnormal ( $\geq$ atypical squamous cells of unknown significance, or ASCUS) cytologic interpretation were also referred for colposcopic evaluation, as was also done with those with a positive Cervi- gram ( $\geq \mathrm{P} 0$, including all positive Cervigram categories from P0 to P3). (P0 means probably normal, but colposcopy recommended to rule out serious neoplasia; P1, probable low grade cervical lesion; P2, probable high grade cervical lesion; and P3, probable cancer). Finally, a $2 \%$ random sample of women from the entire cohort, regardless of diagnosis, were also referred to colposcopy, as a control group.

At the colposcopy clinic, each woman was administered a supplemental questionnaire to assess more extensively her sexual history, medical history, douching, alcohol consumption, occupational history, and exposure to pesticides; the sexual behavior of her partner; and her family history of gynecological cancer. A food frequency questionnaire, concerning the 42 most common sources of selected micronutrients in the Guanacastecan diet, was also included.

For the women referred to colposcopy the study colposcopist/gynecologist, who was highly experienced, performed the examination, and punch biopsies were taken from detected lesions. The colposcopic impression was detailed using standard criteria. Four or five digital colposcopic images were recorded using the DenVu system (DenVu LLC, Tucson, Arizona, United States), with low and high magnification, before and after the application of acetic acid and iodine to the cervix and during the biopsy, if one was taken, to record the exact location. At this clinic, cervical cells were also taken using a Dacron swab for HPV DNA assays, and an additional blood sample was drawn in heparin tubes, separated into its components, and stored to permit micronutrient and other testing. If a cervical intraepithelial lesion grade 2 (CIN 2) or worse ( $\geq$ CIN 2, including more severe neoplasia grade 3 and cervical cancer) was confirmed according to Costa Rican or United States pathologists, the woman was treated following Costa Rican national protocols.

When the natural history study started in mid-1993 the local practice in Guanacaste was to treat women found with $\geq$ CIN 2 with cold-knife conization at either of two hospitals in the province: the Hospital Enrique Baltodano Briceño, in Liberia, and the Hospital de la Anexión, in Nicoya. In early 1994 the study colposcopist/ gynecologist introduced the loop electrosurgical excision procedure (LEEP). This outpatient procedure was included in the colposcopy clinic, and the patients who received this treatment were then referred back to the Costa Rican Social Security Fund (CRSSF) (Caja Costarricense de Seguro Social), to be followed, sometimes by the same collaborating colposcopist/ gynecologist. Costa Rica has a universal health care system provided by the CRSSF, although people are also free to seek health care from private providers.

The biopsy samples were fixed in $10 \%$ buffered formalin, embedded in paraffin, sectioned, stained, and read at a pathology laboratory in Costa Rica, in Cartago province. The paraffin blocks obtained by punch biopsy or LEEP as well as available cone biopsies and hysterectomies from treatment were sent to the United States for review. Final review of all samples will be carried out by a panel of expert pathologists at the NCI, who will assign the final diagnosis to each woman in the cohort.

At the end of the enrollment phase of GP, each woman in the cohort was given a final enrollment diagnosis based on the results of all the tests performed during this phase. The final diagnosis served as the baseline for the active follow-up of different groups from the cohort. All women with suspected $\geq$ CIN 2 were censored from the natural history study, regardless of whether $\geq$ CIN 2 was confirmed.

A computerized information system was available at the local offices in Guanacaste, in Nicoya and Liberia, to register all the data collected in the study, which were periodically sent to the United States for editing. The questionnaires were recorded on a separate database using the double keying feature of the KeyEntry III program (Southern Computer Systems, Inc., Birmingham, Alabama, United States) 
and also sent periodically to the United States. In the United States both sets of information were merged together with laboratory results into one database suitable for analysis after a thorough consistency check.

\section{Design of the follow-up phase}

The GP followed women in the cohort for seven years after enrollment, that is, from 1994 to 2001. The followup phase was designed to study why a small fraction of women infected with $\mathrm{HPV}$, a very common viral infection, develop CIN 2, CIN 3, or cancer. The follow-up period of seven years was chosen to provide adequate numbers of incident outcomes for study, considering the average age of initial infection (late teens) and CIN 2 or CIN 3 diagnosis (mid-twenties to late twenties). The GP has also addressed several issues related to transmission, natural history, and host response to this virus. These answers are essential for the trials of recently developed vaccines against $\operatorname{HPV}(29,30)$, although some related issues remain unknown and deserve further research.

\section{Assignment to follow-up groups.} The diagnosis given at the end of the enrollment phase categorized women into several groups, according to the perceived risk of developing $\geq$ CIN 2 . These groups were followed up at different intervals. Active follow-up was concentrated on the women most likely to develop $\geq$ CIN 2, which served as both the censoring outcome and our surrogate of cancer risk. (We use CIN 3 as the preferred, more certain surrogate in confirmatory analyses.) As stated above, women with any suggestion of $\geq$ CIN 2 occurring at any time during follow-up were censored from the natural history study for ethical reasons, regardless of final diagnosis, with the only exception being those women referred by visual inspection whose colposcopic evaluation was normal.

After overt $\geq$ CIN 2 was ruled out at colposcopy, women with cytologic evidence of low-grade squamous intra- epithelial lesions (LSIL) or koilocytotic atypia (KA) by any of the three techniques and/or comparable histologic diagnoses (CIN 1) were reexamined every six months $(n=492)$. We followed annually women who, at most, had ASCUS cytologic abnormalities or positive Cervigrams suggestive of minor lesions (P0 or P1) $(n=980)$, were HPV DNA-positive by the HC Tube test $(n=$ 303 ), or reported having had five or more sexual partners $(n=344)$. We also selected for annual follow-up a random sample of the remaining normal women $(n=537)$. Finally, we followed annually 410 virgins who were younger than 26 years old at enrollment. Once they became sexually active, these women were seen every six months. The remaining cytologically normal women who were HPV-negative by HC Tube test were assigned to the "passive cohort" ( $n=6034)$ and were referred to the CRSSF for continued routine screening. At five to six years after enrollment, random samples of the passive cohort were invited to a follow-up screening in two sequential waves called "sweeps." A random half were seen at the fifth anniversary $(n=2926)$, and 1000 of the remaining half were randomly selected at the sixth year. The rest of the women in the passive cohort were seen at exit (see below).

Field organization. During the followup phase of the project the field work was coordinated by a general supervisor and two field supervisors, and the clinic work was performed by field teams composed of a nurse, a nurse aide, and an interviewer. The field organization was the same as for enrollment. There was one central office, in San José (the capital and largest city of Costa Rica), and there were two field offices, in Liberia, Guanacaste, and in Nicoya, Guanacaste, that each accounted for around half of the participants. Liberia is located about $225 \mathrm{~km}$ from San José, and Nicoya is approximately $300 \mathrm{~km}$ from the capital. Two clinical teams headed by specially trained nurses worked during followup, one permanently and the other at years five to seven, when we began to rescreen the passive cohort (sweeps). The clinic visits were programmed around the province to facilitate access for the participants. The working teams were driven from either of the Guanacaste local offices to the clinics in one of the study cars, with all the equipment and materials previously packed for the trip. At the end of the daily clinics the samples collected, the equipment used, and the remainders of materials were packed to be returned to the corresponding field office. With the exception of the supervisors and drivers, all staff members were women.

\section{Follow-up visits}

The procedures performed by the study staff at the clinic during followup visits of the women study participants were very similar to those at enrollment. The visits consisted of an interview and a pelvic exam. The pelvic exam included vaginal $\mathrm{pH}$ determination, visual inspection of the cervix, preparation of conventional and liquid-based smears for cytology, collection of additional cells for HPV DNA tests, and two Cervigrams. The pelvic exam was performed only on those women who reported previous sexual activity. At each visit, a blood sample to be used for immunologic and genetic studies was also collected from all women who agreed to the collection, including virgins.

Colposcopy management. If at any follow-up visit there was evidence of a possible $\geq$ CIN 2, the woman was referred to colposcopy, treated as needed, and censored from further follow-up in the cohort, even if the lesion was not confirmed at colposcopy. These women were formally referred for follow-up at the CRSSF. If a woman in active follow-up or one of the sweeps presented with LSIL in any of the screening exams, we assured that she was given appointments for clinic visits at six-month intervals. These women returned to annual screening intervals after two consecutive visits with all screening tests negative. 
Exit from the cohort. For the last year of follow-up (seventh anniversary of enrollment) we scheduled all women in active follow-up and the rest of the women not yet seen from the passive cohort ( $n=2$ 108) for an exit visit, to assure the safety of women participating in the study. At the exit screening and (if necessary) colposcopy visit, very cautious referral and treatment algorithms were instituted to maximize the safety of the exiting cohort members, as described below. At the end of the study, women from the cohort were referred back to the CRSSF, to be screened according to Costa Rican norms.

Interviewer-administered follow-up questionnaires. A standardized questionnaire was administered for demographic and cervical cancer risk factors. The first follow-up questionnaire after the enrollment phase was designed to examine exposures since enrollment. At subsequent visits the questionnaire covered the period since their previous visit. The questionnaires were administered by trained interviewers, and the following topics were included: demographics and education, risk factors related to HPV infection (sexual behavior, partners' sexual behavior), history of any treatment for cervical lesions received outside of the study, reproductive history, use of contraceptives, hormonal replacement therapy, menopause status, and history of smoking (active and passive).

The data collected by interviews showed good reproducibility, according to formal analyses of sexual history questions repeated at different interviews (20).

Pelvic examination and biological samples. Specially trained nurses assisted by a nurse aide performed the pelvic exams during follow-up. After inspection of the external genitalia and cervix, the samples were taken. If a gross abnormality was found during the visual inspection, patients were referred to the study colposcopist for evaluation.
Vaginal $\mathrm{pH}$ was determined with a pHydrion strip (Micro Essential Laboratory, Brooklyn, New York, United States) (pH range 3.0 to 5.5) on a lateral vaginal wall, and then recorded on the study form. Next, cervical cells from the endocervix and the ectocervix were collected for cytology with a Cervex brush, which was rotated 360 degrees five times clockwise, starting at the " 3 o'clock" position on the face of the cervix. A conventional smear was prepared, immediately fixing the cells with Pap Perfect spray (Medscand, Hollywood, Florida, United States). The rest of the cells in the brush were rinsed off by vigorous agitation and pressing into a $20-\mathrm{mL}$ vial of PreservCyt (Cytyc Corporation, Boxborough, Massachusetts, United States) before the brush was discarded. Additional cells were collected for HPV DNA tests, using a Dacron swab and rotating it 360 degrees (one complete rotation) inside the cervical os and then swabbing over the ectocervix (when the squamous columnar junction was outside the endocervical canal). The swab was placed inside a ViraPap DNA transport medium tube (Digene, Gaithersburg, Maryland, United States) and stored in a cooler at $1{ }^{\circ} \mathrm{C}$ to $4{ }^{\circ} \mathrm{C}$ until frozen at $-30^{\circ} \mathrm{C}$ in the field office. When all the cervical samples were collected, two Cervigrams were taken, using a fixed focal length, strobe flash camera (Cerviscope, National Testing Laboratories, High Ridge, Missouri, United States). The nurses were specially trained to be careful to rinse the cervix twice with $5 \%$ acetic acid solution, to remove all visual obstructions such as hair or mucus, and to focus on the os and the ectocervix.

After the pelvic exam, a blood sample was drawn from all women who agreed to the collection. The blood was collected in a $15-\mathrm{mL}$ green top tube, with heparin as anticoagulant. The usual procedures for blood drawing were followed, and the tubes were gently inverted six to eight times to let the blood mix with the heparin. The blood tubes were stored in a cooler at between $1{ }^{\circ} \mathrm{C}$ and $4{ }^{\circ} \mathrm{C}$, avoiding direct contact with the icepacks, until the tubes were delivered to the laboratories, in Nicoya and Liberia, where the processing was performed. Thermometers were used to regularly monitor the temperature inside the coolers, and additional icepacks were added when necessary to maintain the appropriate temperature range. In late 1996 we introduced a new sampling of cervical secretions for immunological studies. Cervical secretions were collected at each follow-up visit for a subset of women believed to be at increased risk of incident $\geq$ CIN 2 because of an LSIL cytology at entry into the cohort or an equivocal cytological finding that was positive for HPV by the HC Tube test at entry into the study $(n=155)$. Cervical secretions were also collected at each of the follow-up visits for a subset of women $(n=354)$ who were cytologically normal, HPV-negative by the HC Tube test, and whose reported sexual behavior suggested low risk of incident $\geq$ CIN 2 (i.e., women who reported fewer than five sexual partners in their lifetime). This group served as a low-risk control group for the highrisk case group defined above. These secretions were also collected at each follow-up visit from women who had been virginal at the time of enrollment, after they reported their sexual debut $(n=249)$. On a random sample of the remaining women under active follow-up, cervical secretion specimens were collected at a single follow-up visit after mid-1996 $(n=303)$. This group comprised a second low-risk control group. Finally, to assure that cervical secretions were collected on all women with incident $\geq$ CIN 2, we also collected cervical secretions from women referred to colposcopy with evidence of $\geq$ CIN 2 ( $n=279$, of which 93 were not in any other group). When cervical secretions were sampled, Weck-Cel surgical sponge spears (Medtronic Solan, Jacksonville, Florida, United States) were used before any other cervical sampling, in order to prevent contamination with blood. One sponge spear was held with a forceps and placed firmly on the cervical os for 30 seconds without rotation, then the procedure was repeated with a second sponge, following the same 
steps, for a total of two specimens per woman. Each sponge was sealed in a 10-mL cryovial with a lid and paraffin paper to prevent evaporation. Cryovials were stored in a cooler at a temperature of between $1{ }^{\circ} \mathrm{C}$ and $4{ }^{\circ} \mathrm{C}$, avoiding direct contact with icepacks, until delivery to the field office at the end of the clinic day, where they were frozen at $-30{ }^{\circ} \mathrm{C}$.

Starting in mid-1998, for a period of 11 months we also evaluated the performance of visual inspection of the cervix aided with acetic acid and magnification, using an AviScope (O'Ryan Industries, Vancouver, Washington, United States), a device developed for this purpose. We studied the utility of this technique for detection of $\geq$ CIN 2 in our population-based cohort (28). During all pelvic exams, if clinical signs of severe vaginitis or cervicitis produced by trichomonas, bacteria, or candida (inflammation, itching, or vaginal discharge) were present, the pelvic exam was deferred until after specific treatment for these conditions. If severe atrophy (manifested by dryness, paleness, or friability of the vaginal epithelium) was observed, the pelvic exam was also deferred until after specific treatment for this condition. Under the supervision of the principal investigators (all medical doctors), the nurses prescribed treatments for any of these conditions, and the medicines were given directly to the woman ( $n=1683$ women, 2739 visits). They were restricted to: metronidazole pills, $2 \mathrm{~g}$ in one dose to the woman and her partner if trichomoniasis or bacterial vaginosis was suspected; ketoconazole pills, $400 \mathrm{mg}$ for five days, or miconazole ovules, one daily for three days, repeating after two weeks, for candidiasis; and Premarin vaginal cream (Ayerst Laboratories, Philadelphia, Pennsylvania, United States), 4 g once a week for four weeks if atrophy was detected.

\section{Modifications to specimen collection procedures}

During follow-up we modified some procedures. Semiautomated PapNet cytology was canceled in 1995, one year after beginning follow-up, because it was found not to add sensitivity to the combination of conventional screening and thin-layer cytology when comparing sensitivity of the different cytology techniques used for screening.

The cervical secretions collection device was replaced with the Ultracell ophthalmic sponges (Ultracell Medical Technologies, North Stonington, Connecticut, United States), because the Weck-Cel was no longer available beginning in mid-2000. The PreservCyt vials were originally processed in the United States using a Cytyc Processor 2000 (Cytyc Corporation, Boxborough, Massachusetts, United States), and the Cytyc thin-layer ThinPrep slides were also read in the United States. Starting in mid-1999, the processing of the vials, the staining, and the screening of the thin-layers was transferred to the cytology laboratory working for the study in Costa Rica, in San José. The laboratory staff were trained and certified in the processing, staining, and reading of the samples by a trainer sent to Costa Rica by the Cytyc Corporation. The Costa Rican cytopathologist (MA) in charge of the laboratory was trained in the United States by the cytopathologist $(\mathrm{MH})$ who read the thin-layers for the study; the Costa Rican cytopathologist also attended a training course at the Cytyc offices. Subsequently, the thin-layer slides processed, screened, and interpreted in Costa Rica were sent with the PreservCyt vials (containing the remaining solution) to the United States for a replicate reading. Both ThinPrep interpretations were incorporated into clinical management.

The collection of cells for DNA tests was also modified during follow-up. The tube for storing the Dacron swab with the cells from the Virapap sampling kit was changed to specimen transport medium in the fall of 1999, when Digene replaced the Hybrid Capture Tube test with Hybrid Capture 2.

The collection of the blood sample had to be modified in mid-1998, after a few years of follow-up, because the $15-\mathrm{mL}$ green top tubes were no longer available. The collection of a single 15$\mathrm{mL}$ tube was replaced by using two 10-mL green top tubes with heparin to collect approximately $16 \mathrm{~mL}$ of blood.

In early 2001 the study investigators decided to set up a field study clinic in Liberia, where women could be given appointments for follow-up visits. Colposcopy was also located in this study clinic. In mid-2002, another field clinic was set up, in Nicoya, for the same purpose.

\section{Transportation, storage, and processing of biological samples}

The transportation, storage, and processing of biological samples presented special challenges, given the very high temperatures and humidity typical in Costa Rica, especially in Guanacaste.

Cervical secretions. The two 10$\mathrm{mL}$ cryovials containing ophthalmic sponges with cervical secretions were placed in a cooler maintained between $1{ }^{\circ} \mathrm{C}$ and $4{ }^{\circ} \mathrm{C}$ in the clinic and stored frozen at $-30{ }^{\circ} \mathrm{C}$ at the field office within five to eight hours. Starting in May 2002 the field study clinic in Liberia was equipped with a liquid nitrogen dry shipper, which allowed samples to be frozen within minutes of collection. These samples are being tested for local cervical immunological parameters postulated to be involved in the host response to genital HPV infection.

Cytology. The smears with cells collected at the field clinics for conventional cytology were sent weekly to a laboratory in San José, where they were stained and screened by cytotechnologists. The study cytopathologist screened all the abnormal smears; in addition, approximately $20 \%$ of the normal smears were rescreened, for quality control purposes. The diagnoses were recorded in the information system and filed in the woman's chart. The staining procedure of the slides presented several problems, most of 
them related to the weather conditions in Costa Rica, which had to be solved through modifications of the staining protocol to achieve and maintain good quality. The PreservCyt vials were placed in a rack in a cooler at $20{ }^{\circ} \mathrm{C}$ after collection and stored at room temperature (air conditioning) in the field offices; the vials were sent to the central office in San José weekly, and shipped periodically to the NCI's biorepository, BBI Biotech Research Laboratories, in Frederick, Maryland, United States, from where they were resent for processing and reading $(\mathrm{MH}$, $\mathrm{CE}$, Women and Infants' Hospital, Providence, Rhode Island, United States). In this cytology laboratory, vials were processed in a Cytyc Processor 2000 (Cytyc Corporation, Boxborough, Massachusetts, United States) to obtain a ThinPrep slide and then stained with the same protocol used for conventional smears. The responsibility for processing the ThinPreps was transferred to the study cytology laboratory in San José, Costa Rica, as mentioned above. Slides prepared and screened in Costa Rica were rescreened in the United States to assure consistency of interpretation throughout the study. Transferring ThinPrep methodology to Costa Rica required considerable effort and will be the subject of a separate report.

HPV DNA. The 10-mL cryovial containing the Dacron swab with cervical cells in $1 \mathrm{~mL}$ of Digene specimen transport medium was placed in a cooler at $1{ }^{\circ} \mathrm{C}$ to $4{ }^{\circ} \mathrm{C}$ in the field clinics and stored frozen at $-30^{\circ} \mathrm{C}$ within five to eight hours at the field office. As described later in this article, we have used several techniques for testing HPV types either individually or grouped. Various articles on the results of these analyses have been published $(4,9,13,15,21,23)$.

Blood samples. The tubes (one 15$\mathrm{mL}$ or two $10-\mathrm{mL}$ ) with collected blood were placed in a cooler at $1{ }^{\circ} \mathrm{C}$ to $4{ }^{\circ} \mathrm{C}$ in the field clinics and sent daily to the processing laboratories in Liberia and Nicoya, where they were centrifuged and aliquoted into plasma, buffy coat, and red blood cells in 2-mL Nalgene cryovials (Nalge Nunc International, Rochester, New York, United States). Aliquoted specimens were stored frozen at $-30^{\circ} \mathrm{C}$ in the field office, transferred in coolers with icepacks to a $-80{ }^{\circ} \mathrm{C}$ freezer in San José on a weekly basis, and periodically shipped on dry ice to the NCI repository in the United States, where they are kept at $-80^{\circ} \mathrm{C}$.

\section{Interpretation of cytologic screening tests and Cervigrams}

The Bethesda System (31) was used to classify both the conventional cytology and the thin-layer cytology, using a standard study form. All cytologic diagnoses were recorded in the information system and filed in the woman's chart. The diagnostic categories were: normal; normal with reactive changes; ASCUS (atypical squamous cells of unknown significance); LSIL (low-grade squamous intraepithelial lesion); HSIL (high-grade squamous intraepithelial lesion), divided into CIN 2 or CIN 3, including carcinoma in situ; squamous carcinoma; and adenocarcinoma. Also, the quality of the smears was reported as adequate, adequate but limited, or inadequate.

Two Cervigrams per woman's visit were recorded, with a total of 20 exposures (10 woman-visits) per film. A sequential exposition number was automatically registered on the Cervigram, to use for identification purposes. Film rolls were sent to National Testing Laboratories in High Ridge, Missouri, United States, for processing and interpretation by an expert colposcopist. The evaluation categories were: negative (no lesion observed), atypical (a lesion of doubtful significance was observed inside or outside of the transformation zone), positive (colposcopic evaluation recommended), and technically defective (not positive but unsuitable for proper evaluation). The positive category was divided into subcategories: P0 (probably normal, but colposcopy recom- mended to rule out serious neoplasia); P1, further categorized as P1A (compatible with trivial disease, but colposcopy recommended because part of the lesion extends into the canal) and P1B (compatible with CIN 1); P2 (compatible with high-grade lesion, either CIN 2 or CIN 3); and P3 (compatible with cancer). The reports that $\mathrm{Na}-$ tional Testing Laboratories sent back to the study were recorded in the information system and filed together with the corresponding photograph in the woman's chart. Photographic versions of the Cervigrams were marked in the most worrisome area, where the interpreting colposcopist in the United States recommended a biopsy. The photographic versions of the Cervigrams were also available to the study colposcopist/gynecologist during his evaluation of the patients.

\section{Colposcopy clinic visit and treatment of cases}

During follow-up only women with one or more screening tests possibly indicating $\geq$ CIN 2 (HPV testing was not considered a screening test for this purpose) were referred to colposcopy. When these reports originated from the United States, they were received at the central study office in San José by one of the Costa Rican investigators by fax or telephone to avoid delays. Patients thought to have a possible severe lesion when unaided visual inspection was done were also referred to colposcopy, regardless of screening tests results. The colposcopy visit was considered an extension of the previous screening visit that motivated referral (to avoid a new interview because of the short interval between the two visits).

During colposcopic evaluation, if the colposcopist saw a lesion consistent with $\geq$ CIN 2 or if the woman had two or more screening tests with HSIL, a LEEP procedure was performed at once. If the lesion was not visually consistent with $\geq$ CIN 2, a biopsy was taken, and the pathology result defined further treatment (Table 1). In other words, given the high colpo- 
TABLE 1. Case management at the regular colposcopy clinic during follow-up, Guanacaste Project, Costa Rica, 1994-2001 a

\begin{tabular}{|c|c|c|c|c|c|}
\hline \multirow[b]{4}{*}{ Referral reason } & \multicolumn{5}{|c|}{ Colposcopic impression } \\
\hline & \multirow[b]{3}{*}{ HSIL } & \multirow[b]{3}{*}{ LSIL } & \multicolumn{2}{|l|}{ Satisfactory } & \multirow[b]{3}{*}{ Unsatisfactory } \\
\hline & & & \multicolumn{2}{|c|}{ Negative } & \\
\hline & & & $\begin{array}{l}\geq 35 \text { years and } \\
\geq 1 \text { child }\end{array}$ & $\begin{array}{c}<35 \text { years or } \\
<1 \text { child }\end{array}$ & \\
\hline $\begin{array}{l}\text { HSIL by conventional cytology } \\
\text { or Cervigram }\end{array}$ & LEEP & $\mathrm{Bx}$ & $\begin{array}{l}\text { Conventional } \\
\text { cytology at } 6 \text { and } \\
12 \text { months }\end{array}$ & $\begin{array}{c}\text { Conventional } \\
\text { cytology at } 6 \text { and } \\
12 \text { months }\end{array}$ & LEEPb \\
\hline HSIL by ThinPrep & LEEP & $\mathrm{Bx}$ & LEEP & $\begin{array}{l}\text { Conventional } \\
\text { cytology at } 6 \text { and } \\
12 \text { months }\end{array}$ & LEEP ${ }^{b}$ \\
\hline HSIL in any two screening tests & LEEP & LEEP & LEEP & $\begin{array}{l}\text { Conventional } \\
\text { cytology at } 6 \text { and } \\
12 \text { months }\end{array}$ & LEEP ${ }^{b}$ \\
\hline HSIL in three screening tests & LEEP & LEEP & LEEP & LEEP & LEEP ${ }^{b}$ \\
\hline
\end{tabular}

scopic referral threshold that led to reasonably high positive predictive value for $\geq$ CIN 2, we employed a "see and treat" protocol if the colposcopic appearance also suggested $\geq$ CIN 2 . All women referred to colposcopy were censored from the study after evaluation and treatment. As a safety measure, women with no lesion observed at the colposcopy (for whom no biopsy was taken) were scheduled for two appointments with the nurse, one at six months and one at one year, for cytologic follow-up with conventional Pap smears (this protocol was implemented four years after the start of the study; before that, women were scheduled for an appointment with the colposcopist and then referred to the CRSSF). Although most women referred to colposcopy were managed according to this protocol, during the first four years of follow-up, women with $\geq$ CIN 2 in the ThinPrep and in any other screening test were treated with LEEP regardless of the colposcopic impression.

All women who were diagnosed with invasive cancer were urgently referred to the CRSSF for further treat- ment according to Costa Rican protocols. Also, all women censored from the study, whether treated or not, were referred back to the CRSSF.

All pathology samples from the colposcopy clinic were processed and evaluated by a pathologist in Costa Rica. Later, they were retrieved and sent to the NCI biorepository for storage and further evaluation. The pathology samples' management protocol was modified several times during follow-up because of changes introduced at the hospitals in Guanacaste. At the beginning all pathology samples were sent to the Dr. Max Peralta Hospital, in Cartago province, for processing and interpretation (Dr. Mena until December 1994). Later, study pathology services moved to the Monseñor Sanabria Hospital in Puntarenas province (Drs. Zamora and González, from January to September 1995), and again back to the Dr. Max Peralta Hospital (Dr. Mena until June 1996, and Dr. Guillén for the remainder of the project). All these modifications involved changes in the processing protocol and interpretation of the samples (e.g., sectioning of the samples and identification of the pieces), which will need to be taken into account during final case assignment now under way. For final case assignment, review of pathology samples from follow-up is taking place at the NCI (MES and Dr. Diane Solomon). A final case diagnosis will be given to each woman in the cohort, for subsequent analyses and for clinical alerts if severe diagnostic disagreements are found that could affect a woman's safety.

\section{HPV testing}

A major goal of the GP is to understand the relationship between HPV infection as measured by HPV DNA testing and subsequent development of $\geq$ CIN 2 as a surrogate of cancer risk. We have applied several state-ofthe-art HPV DNA test methods to the specimens obtained from cohort members. However, the state of the art has evolved during the years of the study.

All HPV testing has been performed on cervical specimens obtained from the cervix with a Dacron swab, as explained above. Initially, we tested all 
enrollment specimens using a prototype of the HC Tube test that was modified mainly to permit the distinction of HPV 16 from the other types in the high-risk probe mix (9). However, we observed that the HC Tube test was inadequate, and so we switched to more sensitive methods, HC 2 and MY09-MY11 consensus primer PCR (2, 9). We tested a risk-stratified random sample of 1250 women to establish the utility of HC 2 as a diagnostic assay that detects, without typing, 13 highrisk HPV types. HC 2 proved very useful, and the minor cross-reactivity with low-risk types is not very important clinically (22). However, epidemiologic studies require typing. We have consequently relied on PCR for the rest of the GP. We have found that a modification of either the polymerase or primers can greatly increase the analytic sensitivity of MY09-MY11 PCR (21) and can alter population prevalence and related risk estimates (Herrero et al., in preparation).

We are testing all of the cervical specimens from the GP in large batches, with numerous masked quality control repeats in order to assess reliability. To maximize the accuracy of testing we are first assaying specimens from certain time periods (e.g., enrollment or years five to seven), then repeating masked tests of all specimens from women of special interest (e.g., cases of incident disease, enrollment HPV 16 DNA-positive) in another large batch. The first approach guarantees independence of measurement for statistical analyses, while the second, "panel" approach permits maximal control for batch variability when examining longitudinal patterns.

\section{Exit from the cohort}

As mentioned before, all women who participated in the study, regardless of having been actively followed up or not, were selected for an exit visit on or around their seventh-year anniversary. The only exception occurred for those censored during follow-up because of suspicion of $\geq \mathrm{CIN}$ 2 in any of the repeated screening

FIGURE 1. Algorithm for referral to colposcopy at the seventh-anniversary visit, Guanacaste Project, Costa Rica, 2001-2002

Seventh-anniversary visit referral to colposcopy

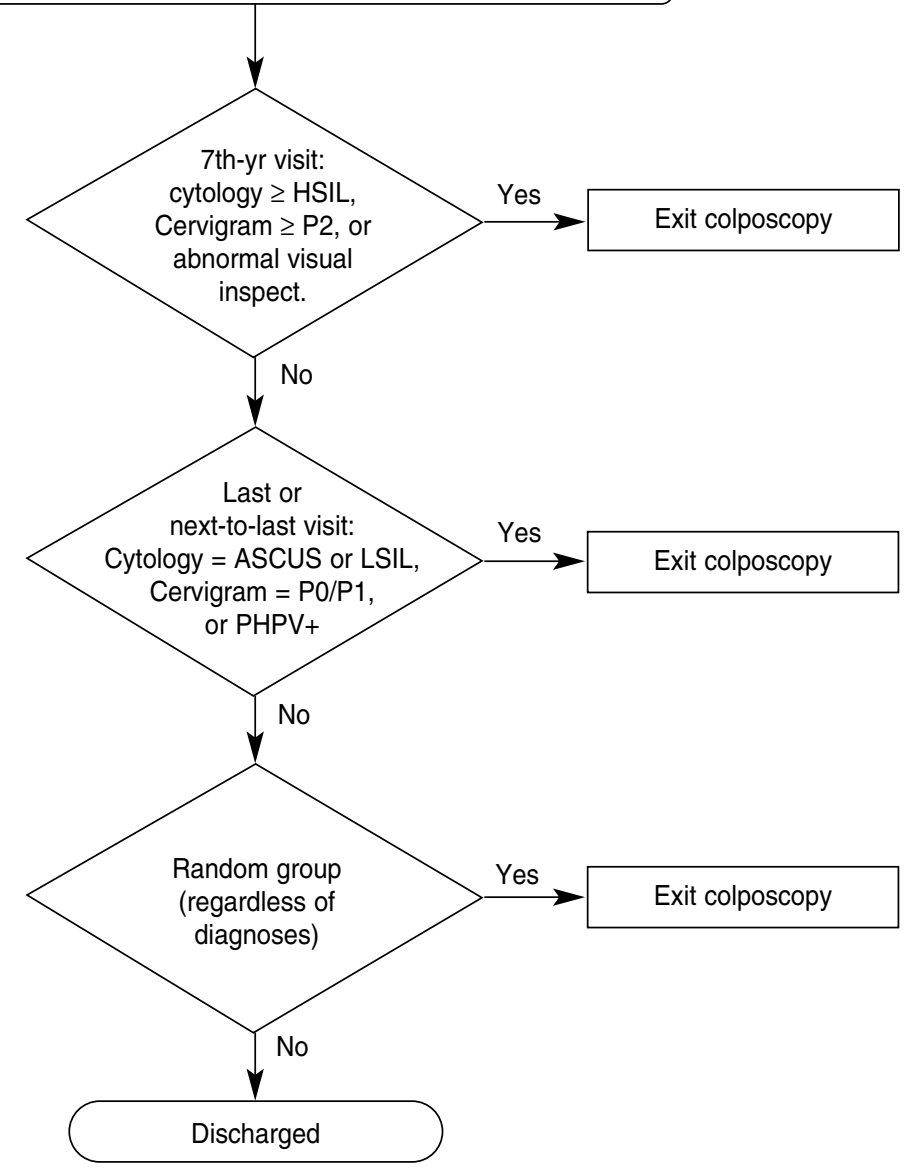

a The abbreviations used in the figure are: HSIL = high grade squamous intraepithelial lesion, ASCUS = atypical squamous cells of unknown significance, LSIL = low grade squamous intraepithelial lesion, PHPV+ = persistent HPV-positive = same HPV type at enrollment and year five or year six, or any type detected at one of these visits and an uncharacterized type at the other time period.

tests, for whom the exit visit was performed at the time of colposcopy and treatment, and for those seen at their fifth or sixth anniversary who were cytologically normal and did not present a persistent HPV infection. For this latter group the exit visit occurred at the fifth or sixth anniversary visit. The exit visit included the same procedures carried out during all other follow-up screening visits. As part of this exit visit we developed a more aggressive colposcopy referral algorithm, whose main goal was to minimize the possibility that women had $\geq$ CIN 2 when leaving the cohort (Figure 1).
At the exit screening visit, as was done throughout follow-up, a woman was referred to colposcopy if she had a cytologic interpretation of HSIL or cancer on either cytologic preparation, a positive Cervigram reported as P2 or P3, or a gross lesion at visual inspection. In addition, at the time of exit, if a woman had an abnormal (ASCUS or LSIL) cytologic interpretation or a positive Cervigram (P0 or P1) in either of the last two screening visits, she attended colposcopy. Also, women with a persistent HPV infection were referred to an exit colposcopy. Persistence was defined as hav- 
TABLE 2. Case management at the exit colposcopy clinic during the seventh-anniversary year, Guanacaste Project, Costa Rica, 2001-2002 ${ }^{a}$

\begin{tabular}{|c|c|c|c|c|c|c|c|c|}
\hline \multirow[b]{4}{*}{ Referral reason } & \multicolumn{8}{|c|}{ Colposcopic Impression } \\
\hline & \multicolumn{5}{|c|}{ Satisfactory } & \multicolumn{3}{|c|}{ Unsatisfactory } \\
\hline & \multicolumn{3}{|c|}{ LSIL } & \multicolumn{2}{|c|}{ Negative } & \multirow[b]{2}{*}{$\begin{array}{l}\text { HSIL } \\
\text { or LSIL }\end{array}$} & \multicolumn{2}{|c|}{ Negative } \\
\hline & HSIL & $\mathrm{H}+$ & $\mathrm{H}-$ & $\begin{array}{l}\geq 35 \text { years } \\
\text { and } \\
\geq 1 \text { child }\end{array}$ & $\begin{array}{c}<35 \text { years, } \\
<1 \text { child, or } \\
\text { severe atrophy }\end{array}$ & & $\mathrm{H}+$ & $\mathrm{H}-$ \\
\hline HSIL by cytology or Cervigram & LEEP & LEEP & LEEP & LEEP & $\begin{array}{l}\text { Colposcopy in } \\
6 \text { months }^{b}\end{array}$ & LEEP & LEEP & LEEP \\
\hline $\begin{array}{l}\text { LSIL, P0, P1, ASCUS, HPV } \\
\text { persistence, }{ }^{C} \text { or abnormal } \\
\text { visual inspection }\end{array}$ & LEEP & LEEP & $B x^{d}$ & $\begin{array}{l}\text { Colposcopy in } \\
6 \text { months }^{b}\end{array}$ & $\begin{array}{l}\text { Colposcopy in } \\
6 \text { months }^{b}\end{array}$ & LEEP & LEEP & $\begin{array}{l}\text { Colposcopy in } \\
6 \text { months }^{b}\end{array}$ \\
\hline Only random control & LEEP & LEEP & $B x^{d}$ & Dismissed & Dismissed & LEEP & $\begin{array}{l}\text { Colposcopy in } \\
6 \text { months }^{b}\end{array}$ & $\begin{array}{l}\text { Colposcopy in } \\
6 \text { months }^{b}\end{array}$ \\
\hline
\end{tabular}

a The abbreviations used in this table are: $\mathrm{HSIL}=$ high grade squamous intraepithelial lesion; LSIL = low grade squamous intraepithelial lesion; ASCUS = atypical squamous cells of unknown significance; $\mathrm{Bx}=$ biopsy; LEEP = loop electrosurgical excision procedure; $\mathrm{H+}=$ positive history = three or more visits and ASCUS or LSIL in $50 \%$ of them or in the last two; $\mathrm{H}-=$ negative history = none of the preceding conditions is true, that is, the woman had fewer than three follow-up visits or ASCUS or LSIL in fewer than $50 \%$ of the visits and both of the two last visits were not ASCUS nor LSIL.

b The second colposcopy included a Pap smear.

${ }^{c}$ HPV persistence $=$ same type of HPV detected at enrollment and 5th or 6th anniversary visits, or any type detected at one of these visits and an uncharacterized type at the other time period.

${ }^{d}$ If the biopsy is negative or LSIL, women are referred to a control colposcopy at 6 months.

ing the same HPV type at enrollment and at the fifth-year or sixth-year visit, or any type detected at one of these visits and an uncharacterized type at the other time period. Finally, $6.25 \%$ of the cohort was randomly referred to the exit colposcopy as a control group, regardless of the diagnoses, to rule out large-scale verification bias.

\section{Management of lesions at the exit colposcopy visit}

The main goal of the exit colposcopy visit was to maximize the detection of $\geq$ CIN 2 and to promote proper treatment for all women with significant lesions.

Management of lesions followed a very strict protocol, as summarized in Table 2. At the exit colposcopy visit all women with possible HSIL indicated by any screening tests were treated with LEEP. The exceptions to this rule were: women younger than 35 years old, those who had no children, or those having severe atrophy (which made LEEP difficult) whose colposcopic evaluation was satisfactory and negative. These unusual women were followed up with colposcopic evalua- tions and conventional Pap smears every six months, until two consecutive negative visits were obtained or a LEEP procedure was performed because an abnormal colposcopic impression suggested CIN (which was the frequent outcome).

If the reason for referral to exit colposcopy was less severe than cytologic or cervicographic evidence of possible HSIL, the LEEP procedure was performed only when the colposcopic impression was satisfactory and possibly indicating HSIL, or possibly indicating CIN 1 and the woman had a "positive history." A positive history was defined as either one of two situations: (1) two immediately preceding screening visits with evidence of ASCUS or LSIL (including P0 or P1 Cervigrams) or (2) $\geq 50 \%$ of three or more follow-up screening visits in the cohort study showing ASCUS or LSIL or P0 or P1 Cervigrams. Finally, in cases where the colposcopic impression at exit was satisfactory and normal, we repeated the colposcopy and conventional cytology after six months in order to obtain two consecutive normal evaluations before dismissing the woman. This was done for all women who had a satisfactory and normal colposcopy, with the exception of women who had been referred to colposcopy only as a random control and whose other tests were normal; for these women no further evaluation was done.

All women treated with LEEP procedure were followed up with a conventional Pap smear and colposcopic evaluation four months after the procedure. If the LEEP margins were reported as free of lesion and the posterior evaluation and Pap smear were normal, the woman was dismissed. If the LEEP margins were not free of lesion or if the colposcopy or Pap smear post treatment was not negative, the woman was sent to two other colposcopic evaluations and conventional Pap smears at 6-month intervals. The purpose was to have two consecutive examinations that were completely normal so as to either dismiss the woman for being free of risk or have her treated to avoid recurrence.

\section{Statistical approach with the follow-up data}

The major statistical analysis of the follow-up data is based on Markov chain methods (32). This approach will 
allow us to examine the detailed natural history of HPV and cervical neoplasia using the full data set, which includes repeated measurements of visual data (colposcopy and cervicography), cytology, histology, molecular markers (DNA and protein markers such as p16), systemic and local immunologic data (serology and markers of cell-mediated immune response), and questionnaire-derived data. The analysis will initially focus on specific HPV types and type variants as well as the origins of highgrade squamous intraepithelial lesions. We will define the prevalence, incidence, and duration of particular types of HPV infection and also identify risk factors for incident and persistent infection in different age groups. In order to determine if the oncogenic HPV types have a different natural history from the low-risk types, we will derive and compare the type-specific duration and risk of progression to high-grade lesion for each HPV type, phylogenetic group, and intratype variant. We will also test the independence of the natural history of each type by analysis of type duration in presence and absence of other types. For these etiologic studies we will divide the clinical endpoint of $\geq \mathrm{CIN} 2$ into CIN 2, CIN 3, and cancer, as defined by the expert pathology review panel.

This unique cohort is derived from an admixed population and provides a natural genetic heterogeneity of host and viral genomes. This will allow us to examine the role of viral heterogeneity and natural selection on phenotypic outcomes (e.g., persistence versus clearance or development of $\geq$ CIN 2), through a comprehensive analysis of the viral genomes in relation to the genetic diversity of the Guanacastecan study population.

\section{RESULTS}

Participation during follow-up was high. Table 3 shows follow-up visits by different "subcohorts." Percentages of women who did not participate at all in follow-up were low, ranging from $1.6 \%$ for women in the 6-monthinterval group to $14.9 \%$ for women in the passive group. Most of the virgins and the women in both the 6-monthinterval group and the 12-monthinterval group had five or more visits $(67.1 \%, 77.1 \%$, and $78.0 \%$, respectively), while $98.2 \%$ of women in the passively followed cohort had one to three follow-up visits (data not shown). The median number of follow-up visits differed for the passive cohort and the active cohort. The medians were one follow-up visit for the passive cohort, six visits for women in the 12month-interval group, and seven visits for women in the 6-month-interval group (Table 3).

The status of women at the end of follow-up is summarized in Table 4. Overall, 341 of the 9100 women (3.7\%) refused to attend a follow-up visit. Among the remaining 8759 women who agreed to be followed, $4.6 \%$ of them were censored with at least one result possibly indicating $\geq$ CIN 2 (although many eventually turned out not to have histologically confirmed $\geq$ CIN 2). Another $10.8 \%$ were cen- sored for other reasons (e.g., 2.6\% were censored due to a hysterectomy for nonneoplastic indications, and $4.5 \%$ were seriously ill or died during follow-up from causes other than cervical cancer).

Most of the women censored because of suspected progression to $\geq$ CIN 2 came from the 12-month follow-up group of the active cohort or from the passive cohort. These groups contributed more possible cases because they were by far the largest in size, although the highest rates of $\geq$ CIN 2 were observed in the 6-month follow-up group, which we had considered a priori to be the highest in progression risk.

The incidence rates of lesions based on Costa Rican histopathology are presented in Table 5. These diagnoses are comparable to Costa Rican clinical practice. However, for study purposes the data will be finalized after completion of final review by the pathology review panel. The total number of womanyears in active follow-up was 52 472.2. As is shown, the confirmed CIN 3 cases plus cancers found during follow-up are 75 , representing a crude incidence rate of 143 cases per 100000 womanyears. The figures for invasive cancer are similar to the crude national rates provided by the National Tumor Registry (NTR) of Costa Rica for the years 1995 to 1999 (range 15.1-17.8), although invasive cancers in our cohort are generally diagnosed at stages that are less advanced. The incidence estimates for CIN 3 lesions are higher for women in the cohort than those in the NTR. The crude national rates for carcinoma in situ reported by the NTR range from

TABLE 3. Number of follow-up visits made, by subcohort, Guanacaste Project, Costa Rica, 1994-2001

\begin{tabular}{lcccc}
\hline & $\begin{array}{c}\text { Virgins } \\
(n=410)\end{array}$ & $\begin{array}{c}\text { 12-month interval } \\
(n=2164)\end{array}$ & $\begin{array}{c}\text { 6-month interval } \\
(n=492)\end{array}$ & $\begin{array}{c}\text { Passive cohort } \\
(n=6 \text { 034) }\end{array}$ \\
\hline Total no. of visits & 2131 & 11019 & 3206 & 6289 \\
Percent with no visits & $5.4 \%$ & $4.1 \%$ & $1.6 \%$ & $14.9 \%$ \\
Mean no. of visits (range) & $5.2(0-11)$ & $5.1(0-12)$ & $6.5(0-12)$ & $1.04(0-5)$ \\
Standard deviation & 2.75 & 2.0 & 2.7 & 0.7 \\
Median no. of visits & 5.0 & 6.0 & 7.0 & 1.0 \\
Mode no. of visits & 5.0 & 6.0 & 8.0 & 1.0 \\
\hline
\end{tabular}


TABLE 4. Status of participants at the end of follow-up, by subcohort and overall, Guanacaste Project, Costa Rica, 2002

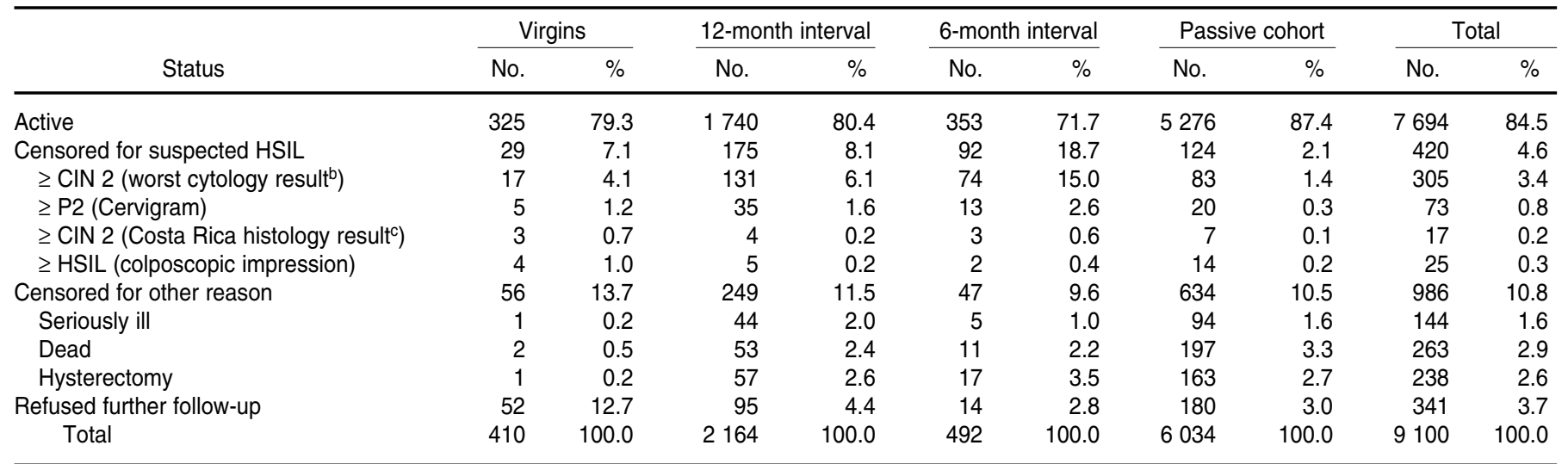

a The abbreviations used in this table are: $\mathrm{HSIL}=$ high grade squamous intraepithelial lesion, CIN 2 = cervical intraepithelial neoplasia grade 2 , P2 = positive 2 Cervigram.

${ }^{b}$ Worst cytology result $=$ worst cytologic result from any of the three evaluations.

${ }^{\mathrm{c}}$ Costa Rica histology result $=$ histologic diagnosis from Costa Rican study pathology laboratory.

20.9 to 31.0 for the same period, probably reflecting not only that we found more lesions because of the intensive screening but also that the NTR underreports this grade of pathology.

The cumulative numbers of biospecimens collected during the follow-up of the GP cohort are shown in Table 6. More than 22000 follow-up questionnaires have also been processed.

\section{DISCUSSION}

The Guanacaste cohort has been followed up actively for seven years, with very high participation rates. We wish to discuss only a few, potentially transferable organizational lessons learned from the long and apparently successful association of so many colleagues in an international molecular epidemiologic research project. The major field effort of the GP is finished. However, the final reviews of visual data, cytologic and histologic specimens, and HPV testing, along with the resultant data analyses, will undoubtedly take several years to complete.

We believe that the GP succeeded because each aspect was supported by intense effort and expertise. The international collaborators in the United States (from the NCI and other institutions) personally trained Costa Rican staff in the United States, San José, and Gua- nacaste. Quality control was continued throughout the study, and the refinement of techniques was maintained until the techniques were optimized. It was essential to hire and retain excellent field project staff. Paying good wages to excellent personnel at all levels is important for staff retention, although this may be contentious both in the site selected for research and at the donor institution. However, the highquality GP staff in Costa Rica, together with the collaboration of the international investigators, made the Guanacaste Project successful. At any time, it would have been much more costly and disruptive to lose field staff than to recognize and appropriately reward their world-class expertise.

It is possible-and in fact important-to adapt new diagnostic and screening technology invented in hightechnology areas to regions of need such as rural Guanacaste. We transferred LEEP to Guanacaste early in the project. The transfer of other study technology, including visual screening, thin-layer cytology, and HPV testing, is technically complete but still too expensive for countrywide adoption, regardless of the demonstrated improved accuracy. We continue to press for affordable adaptations of new cervical cancer prevention technologies. We believe that this female population was willing to participate in the study not only for their own safety but also in the hope that their efforts would guide the way toward a diminished risk of cervical cancer for the following generations. To validate a technology in an area that cannot ultimately use

TABLE 5. Preliminary incidence rates for high grade lesions and cancer, Guanacaste Project, Costa Rica, 2002a

\begin{tabular}{lrr}
\hline Histologically confirmed lesions & No. of cases & Rate $^{\text {b }}$ \\
\hline CIN 2 & 110 & 210 \\
CIN 3 $^{\text {d }}$ & 67 & 128 \\
Cancer & 8 & 15 \\
\hline a These results are based only on Costa Rican histologic results. Final results will be published \\
after the final diagnosis is defined for each woman in the cohort, after the review of slides is \\
finished at the National Cancer Institute of the United States. \\
${ }^{b}$ Rates are cases per 100 000 woman-years of follow-up. \\
${ }^{c}$ CIN 2 = cervical intraepithelial neoplasia grade 2. \\
${ }^{d}$ CIN 3 = cervical intraepithelial neoplasia grade 3.
\end{tabular}


TABLE 6. Number of biospecimen samples collected during follow-up, Guanacaste Project, Costa Rica, 1994-2002

\begin{tabular}{lcccccccc}
\hline $\begin{array}{c}\text { Cells in } \\
\text { PreservCyt }\end{array}$ & $\begin{array}{c}\text { Swabs for } \\
\text { DNA }\end{array}$ & $\begin{array}{c}\text { Pap } \\
\text { smears }\end{array}$ & $\begin{array}{c}\text { ThinPrep } \\
\text { smears }\end{array}$ & $\begin{array}{c}\text { Cervical } \\
\text { secretions }\end{array}$ & $\begin{array}{c}\text { RBC } \\
\text { vials }\end{array}$ & $\begin{array}{c}\text { WBC } \\
\text { vials }\end{array}$ & $\begin{array}{c}\text { Plasma } \\
\text { vials }\end{array}$ & $\begin{array}{c}\text { Tissue } \\
\text { samples }\end{array}$ \\
\hline 20883 & 21485 & 18838 & 19397 & 6276 & 22408 & 22410 & 106816 & 1802 \\
\hline $\begin{array}{l}\text { a RBC }=\text { red blood cells. } \\
\text { b } \text { WBC }=\text { white blood cells. }\end{array}$
\end{tabular}

it (because of unavailability or cost) would be fruitless in our opinion and contrary to the cohort members' spirit of cooperation.

Projects such as the GP require teams of many committed and mutually trusting professionals spending large parts of their careers on common goals. The links to the community must be equally strong in order to achieve nearly universal enrollment and follow-up. In the absence of simple trust, no amount of information technology, site visiting, or contracts management could guarantee quality, given the distances between sites and time lags in data transfer and review.

Below we emphasize some of the issues that should be addressed carefully when designing a long study such as this one:

- The investigators must dedicate special attention to protocol details when designing the study, which will ensure the successful completion of the longterm follow-up. Also, expert advice is needed throughout the study, from its design until its closeout, to assure that the best techniques are used.

- Extensive training before initiation of the study and during the study is a key element for the study to be successful.

- Quality control and protocol adherence should be implemented from the start of the investigation, in order to avoid extra work fixing problems once the project is under way.

- Permanent supervision and periodic site visits from the expert collaborators are recommended to assure that good quality is maintained, given that quality can decline due to the demands of a heavy workload.

- Documenting all the changes made to the protocol or procedures is absolutely essential, in order to facilitate the analyses made years after those changes have been made.

- Extraordinary commitment from all the staff is essential, especially the persons working in the field who are in direct contact with study participants. Funding and other resources must be available as programmed, to avoid unnecessary delays, especially in the planned field work, and to allow selection and retention of qualified and experienced staff.

Costa Rica's universal (Social Security) health care system has an extensive network of health care providers, and the country also has an educated population willing to cooperate in health research efforts. Those characteristics were key to the success of the study.

The GP is the largest populationbased longitudinal cohort that has studied HPV and cervical neoplasia in the world. The results from this study have been important in validating sensitive screening techniques and also in looking for more affordable techniques to be used in resource-poor regions (25). The knowledge that HPV infection with HPV types 16 and 18 causes more than $60 \%$ of cervical cancer worldwide (33), as has been confirmed in Guanacaste, has led to the production of vaccines with these types in an effort to develop an effec- tive tool to reduce the incidence and mortality of this cancer worldwide.

The strong support of Guanacastecan and national Costa Rican health authorities was another essential component of this successful effort. An even higher level of cooperation will be needed for the intervention trial that has been planned to start later this year. In this trial, healthy young women in Guanacaste will be vaccinated against two HPV types (16 and 18). The hope is to have available a worldwide preventive method against cervical cancer in the near future.

Finally, we believe that this study has clearly shown that major, important research is feasible in a developing country, particularly in the context of cooperative efforts.

Acknowledgements. We wish to acknowledge the collaboration of local health authorities and all our staff in Guanacaste devoted to the field work, who made it possible for this major effort to be successful. We also express our special gratitude to the people at Information Management Systems, Inc., who helped us with data management, and the staff of Biotech BBI Inc., who provided support with shipments and repository issues. This study was supported by Public Health Services (PHS) of the United States contracts N01CP 21081, N01CP 33061, N01CP 40542, N01CP 50535, and N01CP 81023 between the National Cancer Institute of the United States and FUCODOCSA (Costa Rican Foundation for Training in Health Sciences). 


\section{REFERENCES}

1. Herrero R, Schiffman M, Bratti C, Hildesheim A, Balmaceda I, Sherman ME, et al. Design and methods of a population-based natural history study of cervical neoplasia in a rural province of Costa Rica: the Guanacaste Project. Rev Panam Salud Publica. 1997;1(5):362375.

2. Herrero R, Hildesheim A, Bratti C, Sherman M, Hutchinson M, Morales J, et al. Population-based study of human papillomavirus infection and cervical neoplasia in rural Costa Rica. J Natl Cancer Inst. 2000;92:464-474.

3. Hildesheim A, Herrero R, Castle PE, Wacholder S, Bratti MC, Sherman ME, et al. HPV co-factors related to the development of cervical cancer: results from a population-based study in Costa Rica. Br J Cancer. 2001;84(9): 1219-1226.

4. Hildesheim A, Schiffman M, Bromley C, Wacholder S, Herrero R, Rodríguez AC, et al. Human papillomavirus type 16 variants and risk of cervical cancer. J Natl Cancer Inst. 2001;93(4):315-318.

5. Ung A, Kramer T, Schiffman M, Herrero R, Bratti MC, Swanson C, et al. Soluble interleukin 2 receptor levels and cervical neoplasia: results from a population-based casecontrol study in Costa Rica. Cancer Epidemiol Biomarkers Prevent. 1999;8:249-253.

6. Hildesheim A, Martin M, Schiffman M, Herrero R, Bratti MC, Schwartz P, et al. p53 polymorphism and risk of cervical cancer. Nature. 1998;396:530-532.

7. Herrero R, Schiffman M, Hildesheim A, Bratti $\mathrm{C}$, Rodríguez AC, Sherman ME, et al. Is cervical cancer cytological screening valuable in developing countries? In: Franco E, Monsonego J, eds. New developments in cervical cancer screening and prevention. Cambridge, United Kingdom: Blackwell Science Ltd; 1997. Pp. 241-249.

8. Herrero R, Schiffman M, Bratti C, Hildesheim A, Sherman M, Morales J, et al. Evaluation of multiple screening techniques in a high-risk area: the Guanacaste project. In: Franco E, Monsonego J, eds. New developments in cervical cancer screening and prevention. Cambridge, United Kingdom: Blackwell Science Ltd; 1997. Pp. 389-399.

9. Schiffman M, Herrero R, Hildesheim A, Sherman M, Bratti C, Wacholder S, et al. HPV DNA testing in cervical cancer screening. JAMA. 2000;283:87-93.

10. Hutchinson M, Zahniser D, Sherman M, Herrero R, Alfaro M, Bratti MC, et al. Utility of liquid-based cytology for cervical carcinoma screening. Cancer Cytopathol. 1999;87:48-55.

11. Sherman M, Schiffman M, Herrero R, Kelly D, Bratti C, Mango L, et al. Performance of a semiautomated Papanicolaou smear screening system. Cancer Cytopathol. 1998;84:273280.
12. Schneider D, Herrero R, Bratti C, Greenberg M, Hildesheim A, Sherman M, et al. Cervicography screening for cervical cancer among 8460 women in a high-risk population. Am J Obstet Gynecol. 1999;180:290-298.

13. Sherman M, Schiffman M, Lorincz A, Herrero $\mathrm{R}$, Hutchinson M, Bratti C, et al. Cervical specimens collected in liquid buffer are suitable for both cytologic screening and ancillary human papillomavirus testing. Cancer Cytopathol. 1997;81:89-97.

14. Hildesheim A, Bratti C, Edwards R, Schiffman M, Rodriguez AC, Herrero R, et al. Collection of cervical secretions does not adversely affect Pap smears taken immediately afterward. Clin Diagn Lab Immunol. 1998;5:491-493.

15. Peyton C, Schiffman M, Lorincz A, Hunt W Mielzynska I, Bratti C, et al. Comparison of PCR- and hybrid capture-based human papillomavirus detection systems using multiple cervical specimen collection strategies. J Clin Microbiol. 1998;36:3248-3254.

16. Hildesheim A, McShane L, Schiffman M, Bratti C, Rodríguez AC, Herrero R, et al. Cytokine and immunoglobulin concentrations in cervical secretions: reproducibility of the Weck-cel collection instrument and correlates of immune measures. J Immunol Methods. 1999;225;131-143.

17. García-Closas M, Herrero R, Bratti C, Hildesheim A, Sherman M, Morera L, et al. Epidemiologic determinants of vaginal $\mathrm{pH}$. Am J Obstet Gynecol. 1999;180:1060-1066.

18. Castle P, Hillier S, Rabe L, Hildesheim A, Herrero R, Bratti M, et al. An association of cervical inflammation with high-grade cervical neoplasia in women infected with oncogenic human papillomavirus (HPV). Cancer Epidemiol Biomarkers Prev. 2001;10(10):10211027.

19. Wang $S$, Wheeler $C$, Hildesheim A, Schiffman M, Herrero R, Bratti M, et al. Human leukocyte antigen class I and II alleles and risk of cervical neoplasia: results from a populationbased study in Costa Rica. J Infect Dis. 2001; 184:1310-1314.

20. Schlecht NF, Franco EL, Rohan TE, Kjaer SK, Schiffman MH, Moscicki A-B, et al. Repeatability of sexual history in longitudinal studies on HPV infection and cervical neoplasia: determinants of reporting error at follow-up interviews. J Epidemiol Biostat. 2001;6:393-407.

21. Castle PE, Schiffman M, Gravitt PE, Hildesheim A, Herrero R, Bratti MC, et al. Comparisons of HPV DNA detection by MY09/11 PCR methods. J Med Virol. 2002;68:417-423.

22. Castle PE, Solomon D, Hildesheim A, Herrero $\mathrm{R}$, Bratti MC, Sherman ME, et al. Stability of archived liquid-based cervical cytologic specimens. Cancer Cytopathol. 2003;99(2):89-96.

23. Castle PE, Schiffman M, Burk RD, Wacholder S, Hildesheim A, Herrero R, et al. Restricted cross-reactivity of hybrid capture 2 with nononcogenic human papillomavirus types. Cancer Epidemiol Biomarkers Prevent. 2002;11: 1394-1399.

24. Castle PE, Phillips TM, Hildesheim A, Herrero R, Bratti MC, Sherman ME, et al. Immune profiling of plasma and cervical secretions using recycling immunoaffinity chromatography. Cancer Epidemiol Biomarkers Prevent. 2003;12:1449-1456.

25. Jeronimo J, Castle PE, Herrero R, Burk RD, Hildesheim A, Bratti MC, et al. HPV testing and visual inspection for cervical cancer screening in resource-poor regions. Int J Gynaecol Obstet. 2003;83:311-313.

26. Ferreccio C, Bratti MC, Sherman ME, Herrero R, Wacholder S, Hildesheim A, et al. A comparison of single and combined visual, cytologic, and virologic tests as screening strategies in a region at high risk of cervical cancer. Cancer Epidemiol Biomarkers Prevent. 2003; 12:815-823.

27. Viscidi RP, Schiffman M, Hildesheim A, Herrero $\mathrm{R}$, Castle PE, Bratti $\mathrm{MC}$, et al. Seroreactivity to human papillomavirus (HPV) types 16,18 or 31 and risk of subsequent HPV infection: results from a population-based study in Costa Rica. Cancer Epidemiol Biomarkers Prevent. Forthcoming 2004.

28. Rodríguez AC, Morera LA, Bratti C, Herrero $\mathrm{R}, \operatorname{Cox} \mathrm{T}$, Morales JL, et al. Performance of direct visual inspection of the cervix with acetic acid and magnification in a previously screened population. J Lower Genital Tract Dis. Forthcoming 2004.

29. Schiller JT, Hildesheim A. Developing HPV virus-like particle vaccines to prevent cervical cancer: a progress report. J Clin Virol. 2000;19: 67-74.

30. Schiller JT, Lowy DR. Papillomavirus-like particle vaccines. J Natl Cancer Inst Monogr. 2001;28:50-54.

31. The 1988 Bethesda System for reporting cervical/vaginal cytologic diagnoses. $\mathrm{Na}$ tional Cancer Institute Workshop. JAMA. 1989;262:931-934.

32. Myers ER, McCrory DC, Nanda K, Bastian L, Matchar DB. Mathematical model for the natural history of human papillomavirus infection and cervical carcinogenesis. Am J Epidemiol. 2000;151(12):1158-1171.

33. International Agency for Research on Cancer. Human papillomaviruses. Lyon, France: IARC; 1995. (IARC Monographs on the Evaluation of Carcinogenic Risks to Humans 64).

Manuscript received 9 December 2002. Revised version accepted for publication on 13 May 2003 
RESUMEN Objetivos. El estudio de cohorte de Guanacaste, o Proyecto Epidemiológico Guanacaste, fue diseñado para investigar el papel que desempeñan la infección por el virus del papiloma humano (VPH) y sus cofactores en el desarrollo de neoplasias cervicouterinas y para evaluar nuevas tecnologías de tamizaje del cáncer del cuello de útero. La fase de seguimiento de este proyecto se diseñó para analizar por qué una pequeña parte de las mujeres infectadas por el VPH desarrollan neoplasias intraepiteliales cervicouterinas (NIC) grados 2 y 3, o cáncer (que en lo adelante se llamarán en conjunto $\geq$ NIC 2, es decir, NIC 2 o peor). El propósito de este artículo es describir en detalle ese estudio prospectivo y presentar los resultados preliminares relacionados con la incidencia de neoplasias cervicouterinas.

Métodos. Se realizó el tamizaje intensivo de una cohorte de 10049 mujeres de 18 a 97 años de edad seleccionadas aleatoriamente en Guanacaste, provincia del noroeste de Costa Rica, en 1993-1994 con un seguimiento ulterior de siete años. A las participantes se les aplicó un cuestionario para conocer sus características demográficas y sus factores de riesgo, y a las sexualmente activas se les realizó además un examen pélvico en cada una de las visitas de seguimiento, a fin de obtener muestras para las pruebas de tamizaje y la investigación. El diagnóstico obtenido al final de la fase de captación permitió clasificar a las mujeres en varios grupos de acuerdo con el riesgo que presentaban de desarrollar cáncer o alguno de sus precursores de alto grado. Estos grupos tuvieron seguimientos a intervalos diferentes, según su riesgo de desarrollar $\geq$ NIC 2. El seguimiento más activo (cada 6-12 meses) se concentró en las mujeres con mayores probabilidades de desarrollar $\geq$ NIC 2, según los resultados citológicos $(n=$ 492). Las mujeres restantes recibieron visitas de seguimiento anualmente $(n=2574)$ o después de cinco a siete años de seguimiento pasivo $(n=3926)$. A todas las mujeres en quienes se detectaron lesiones que pudieran ser graves, por cualquiera de las técnicas empleadas, se les remitió a una evaluación ulterior mediante colposcopia y a tratamiento médico, y se retiraron del estudio. Las lesiones $\geq$ NIC 2 se utilizaron como criterio para la salida del estudio y como indicadores indirectos del riesgo de cáncer. Resultados. La participación durante la fase de seguimiento fue alta (cercana al $90 \%$ ). Cualquier indicio de $\geq$ NIC 2, según cualquiera de las técnicas de tamizaje, fue motivo para eliminar a 4,6\% de las mujeres participantes. La mayor parte de estas mujeres procedían del grupo que al inicio del estudio parecía tener un riesgo bajo de desarrollar $\geq$ NIC 2, pero el mayor riesgo absoluto de progresión a $\geq$ NIC 2 a partir de lesiones intraepiteliales escamosas de bajo grado se observó entre las mujeres que al incorporarse al estudio parecían estar en mayor riesgo de $\geq$ NIC 2 según los resultados citológicos y virológicos y su comportamiento sexual.

Conclusiones. El Proyecto Epidemiológico Guanacaste es el estudio de cohorte de base poblacional de neoplasia cervicouterina más grande del mundo y se espera que sus resultados permitan elaborar en un futuro cercano estrategias preventivas en todo el mundo. Proyectos de investigación como este requieren del compromiso a largo plazo de un numeroso equipo multidisciplinario y de considerables recursos financieros. El intenso esfuerzo y la gran pericia demostrados en todas las facetas de este estudio constituyeron factores clave que explican su éxito como modelo de investigación cooperativa interdisciplinaria sobre el cáncer en América Latina. El control de la calidad desempeñó un papel importante en todas las etapas de la investigación y permitió adaptar las nuevas tecnologías de diagnóstico y tamizaje a las condiciones de Guanacaste. El seguimiento sistemático de un grupo poblacional de aproximadamente 10000 mujeres de Guanacaste debe permitir una evaluación cuidadosa y cronológica de los factores que diversos autores han asociado con el desarrollo de cáncer cervicouterino, así como la evaluación de marcadores clínicos de la progresión de esta enfermedad. En los resultados publicados de este estudio se definen las técnicas de tamizaje más sensibles y se promueve la utilización de técnicas de tamizaje más asequibles para países en desarrollo y con pocos recursos. Este proyecto también ha aportado información útil para la búsqueda de vacunas contra los VPH, como parte de las iniciativas dirigidas a desarrollar vías eficaces para reducir la incidencia del cáncer cervicouterino y la mortalidad que ocasiona en todo el mundo. 